\title{
Determinants of Glycated Hemoglobin in Subjects With Impaired Glucose Tolerance: Subanalysis of the Japan Diabetes Prevention Program
}

\author{
Naoki Sakane a, q, Juichi Sato ${ }^{b}$, Kazuyo Tsushita ${ }^{c}$, Satoru Tsujii ${ }^{\mathrm{d}}$, Kazuhiko Kotania, e, \\ Makoto Tominaga ${ }^{\mathrm{f}}$, Shoji Kawazu ${ }^{\mathrm{g}}$, Yuzo Sato ${ }^{\mathrm{h}}$, Takeshi Usui ${ }^{\mathrm{i}}$, Isao Kamaej, Toshihide Yoshida ${ }^{\mathrm{k}}$, \\ Yutaka Kiyohara ${ }^{1}$, Shigeaki Sato ${ }^{m}$, Kokoro Tsuzaki ${ }^{a}$, Shinsuke Nirengi ${ }^{a}$, Kaoru Takahashi ${ }^{a}$, , \\ Hideshi Kuzuya ${ }^{\mathrm{a}, \mathrm{o}}$, JDPP Research Group ${ }^{\mathrm{p}}$
}

\begin{abstract}
Background: Limited evidence is available about the relationship of lifestyle factors with glycated hemoglobin (HbAlc) in subjects with impaired glucose tolerance. The aim of study was to identify such determinant factors of $\mathrm{HbA1c}$ in subjects with impaired glucose tolerance.

Methods: This cross-sectional study included 121 men and 124 women with impaired glucose tolerance, who were diagnosed based on a 75-g oral glucose tolerance test. Demographic and biochemical parameters, including the body mass index (BMI), fasting plasma glucose (FPG), 2-h post-load glucose (2-h PG), and HbAlc, were
\end{abstract}

Manuscript accepted for publication January 26, 2017

aDivision of Preventive Medicine, Clinical Research Institute, National Hospital Organization Kyoto Medical Center, Kyoto, Japan

bDepartment of General Medicine/Family \& Community Medicine, University Graduate School of Medicine, Nagoya, Japan

${ }^{\mathrm{c} C o m p r e h e n s i v e ~ H e a l t h ~ S c i e n c e ~ C e n t e r, ~ A i c h i ~ H e a l t h ~ P r o m o t i o n ~ F o u n d a t i o n, ~}$ Higashiura-cho, Aichi, Japan

${ }^{\mathrm{d} D i a b e t e s}$ Center, Tenri Yorozu-sodansho Hospital, Tenri, Japan

e Division of Community and Family Medicine, Jichi Medical University, Tochigi, Japan

fDivision of Internal Medicine, Hananoie Hospital, Tochigi, Japan

gDepartment of Diabetes and Metabolism, Marunouchi Hospital, The Institute for Adult Diseases, Asahi Life Foundation, Tokyo, Japan

${ }^{\mathrm{h}}$ The Graduate Center of Human Science, Aichi Mizuho College, Nagoya, Japan

iDivision of Endocrinology, Clinical Research Institute, National Hospital Organization Kyoto Medical Center, Kyoto, Japan

${ }^{\mathrm{j}}$ Graduate School of Public Policy, The University of Tokyo, Tokyo, Japan

kObesity and Diabetes Center, Shimabara Hospital, Kyoto, Japan

${ }^{1}$ Department of Medicine and Clinical Science, Graduate School of Medical

Sciences, Kyusyu University, Fukuoka, Japan

mHirakata General Hospital for Developmental Disorders, Hirakata, Osaka, Japan

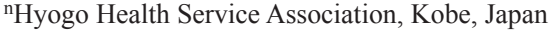

'Higashiyama Takeda Hospital, Kyoto, Japan

pThe Japan Diabetes Prevention Program Research Group

${ }^{q}$ Corresponding Author: Naoki Sakane, Division of Preventive Medicine, Clinical Research Institute, National Hospital Organization Kyoto Medical Center, 1-1 Fukakusamukaihata-cho, Fushimi-ku, Kyoto 612-8555, Japan.

Email: nsakane@kyotolan.hosp.go.jp

doi: https://doi.org/10.14740/jocmr2928w measured. The pancreatic $\beta$-cell function and insulin resistance were assessed using homeostasis model assessment (HOMA- $\beta$ ). Dietary intake was assessed by a food frequency questionnaire.

Results: The levels of FPG, 2-h PG, and carbohydrate intake were correlated with the HbA1c level in men, while the FPG and 2-h PG levels were correlated with the HbAlc level in women. In multiple regression analyses, BMI, FPG, 2-h PG, and white rice intake were associated with $\mathrm{HbA} 1 \mathrm{c}$ levels in men, while BMI, FPG, HOMA- $\beta$, and bread intake were associated with $\mathrm{HbAlc}$ levels in women.

Conclusions: The present findings suggest that a substantial portion of HbA1c may be composed of not only glycemic but also several lifestyle factors in men with impaired glucose tolerance. These factors can be taken into consideration as modifiable determinants in assessing the HbAlc level for the diagnosis and therapeutic monitoring of the disease course.

Keywords: Bread; Carbohydrate; Diabetes; Glycosylated hemoglobin; White rice

\section{Introduction}

The prevalence of type 2 diabetes is increasing globally, placing a heavy burden on the public health and socioeconomic development of all nations [1]. Type 2 diabetes is a multifactorial disease due to the combination of environmental and genetic risk factors. Many environmental risk factors contribute to the pathogenesis of type 2 diabetes, including lifestyles such as sedentary behavior, unhealthy diet, smoking, and alcohol consumption. Measuring glycated hemoglobin (HbAlc) has long been fundamental to managing patients with diabetes. HbAlc is not only used to monitor long-term glycemic control (representing the average blood glucose concentration over the previous 8 - 12 weeks), but also to adjust therapy, assess the quality of care, and predict the risk for the development of complications in subjects with impaired glucose metabolism [2-6].

Exploring the determinants of $\mathrm{HbA} 1 \mathrm{c}$ is thus important. The $\mathrm{HbAlc}$ level has been reported to be associated with lifestyle-related factors such as smoking, dietary factors, and alcohol drinking in the general population [7-9]. Carbohydrate intake has 
Table 1. Population Characteristics of Men and Women With Impaired Glucose Tolerance in the Japan Diabetes Prevention Study

\begin{tabular}{|c|c|c|c|}
\hline Parameters & Men $(n=121)$ & Women $(n=124)$ & P-value \\
\hline \multicolumn{4}{|l|}{ Demographic parameters } \\
\hline Age, years & $50.0(46.0-56.0)$ & $53.0(49.5-57.0)$ & $<0.01$ \\
\hline BMI, kg/m² & $24.7(23.2-26.6)$ & $23.2(21.9-26.0)$ & 0.15 \\
\hline Waist circumference, $\mathrm{cm}$ & $88.4(83.0-92.0)$ & $80.5(74.3-88.0)$ & $<0.01$ \\
\hline \multicolumn{4}{|l|}{ Blood pressure } \\
\hline Diastolic blood pressure, $\mathrm{mm} \mathrm{Hg}$ & $80.0(74.0-89.0)$ & $80.0(72.0-86.0)$ & 0.24 \\
\hline \multicolumn{4}{|l|}{ Metabolic parameters } \\
\hline Fasting plasma glucose, $\mathrm{mmol} / \mathrm{L}$ & $6.1(5.8-6.5)$ & $5.8(5.5-6.3)$ & $<0.01$ \\
\hline 2-h post-load plasma glucose, $\mathrm{mmol} / \mathrm{L}$ & $9.1(8.4-10.0)$ & $8.8(8.2-9.6)$ & 0.03 \\
\hline $\mathrm{HbA} 1 \mathrm{c}, \%$ & $5.7(5.4-6.0)$ & $5.8(5.6-6.0)$ & $<0.01$ \\
\hline HDL-cholesterol, mmol/L & $1.3(1.2-1.6)$ & $1.5(1.3-1.7)$ & $<0.01$ \\
\hline \multicolumn{4}{|l|}{ Dietary factors } \\
\hline Total energy intake, kcal & $2,471.1(1,857.8-3,099.9)$ & $2,123.2(1,810.1-2,542.0)$ & $<0.01$ \\
\hline Protein intake, $\mathrm{g}$ & $86.7(67.0-118.2)$ & $89.2(70.8-112.3)$ & 0.46 \\
\hline Fat intake, $g$ & $67.4(46.1-96.3)$ & $64.4(55.1-87.0)$ & 0.49 \\
\hline Carbohydrate intake, $g$ & $305.9(248.3-366.7)$ & $283.8(241.6-331.6)$ & 0.06 \\
\hline Alcohol intake, $g$ & $22.5(4.0-51.1)$ & $0.4(0.0-2.9)$ & $<0.01$ \\
\hline \multicolumn{4}{|l|}{ Main carbohydrate-containing foods } \\
\hline White rice, $\mathrm{g}$ & $111.3(81.1-172.4)$ & $89.0(65.9-109.8)$ & $<0.01$ \\
\hline
\end{tabular}

BMI: body mass index; HOMA-IR: homeostasis model assessment-insulin resistance; HOMA- $\beta$ : homeostasis model assessment-beta-cell function; HDL: high-density lipoprotein. The values are the percentage and median (25th - 75th percentiles).

also been suggested to be one of the factors associated with the $\mathrm{HbA} 1 \mathrm{c}$ level and, in fact, there is a report showing that the substitution of fat for carbohydrate was associated with low HbA1c levels in diabetic patients with high-level energy consumption [10]. However, limited evidence is available on the relationship of lifestyle factors with $\mathrm{HbAlc}$ in subjects with impaired glucose tolerance. The aim of the study was to examine such factors of HbA1c in subjects with impaired glucose tolerance.

\section{Materials and Methods}

\section{Participants}

Subjects with impaired glucose tolerance, aged 30 - 60 years, were recruited through health checkups conducted at each collaborative center. Recruitment started in March 1999 and was completed in December 2002. A two-step strategy was adopted for identifying those with impaired glucose tolerance as described previously [11]. Using the data from health checkups, those who met one of the following criteria were extracted: 1 ) fasting plasma glucose (FPG) concentration $\geq 5.6 \mathrm{mmol} / \mathrm{L}$ but $<$ $7.0 \mathrm{mmol} / \mathrm{L}, 2)$ casual plasma glucose $(\mathrm{PG})$ concentration $\geq 7.8$ $\mathrm{mmol} / \mathrm{L}$ but $<11.1 \mathrm{mmol} / \mathrm{L}$ when blood was drawn within $2 \mathrm{~h}$ after a meal, or casual PG concentration $\geq 6.1 \mathrm{mmol} / \mathrm{L}$ but $<7.8$ $\mathrm{mmol} / \mathrm{L}$ when blood was drawn $2 \mathrm{~h}$ or more after a meal, or 3 ) impaired glucose tolerance as indicated by a previous 75 -g oral glucose tolerance test (OGTT). The subjects were examined by the 75-g OGTT if they fulfilled any one of the above mentioned criteria. The definition of impaired glucose tolerance was based on the WHO's criteria $[12,13]$. Those with: 1) a previous diag- 

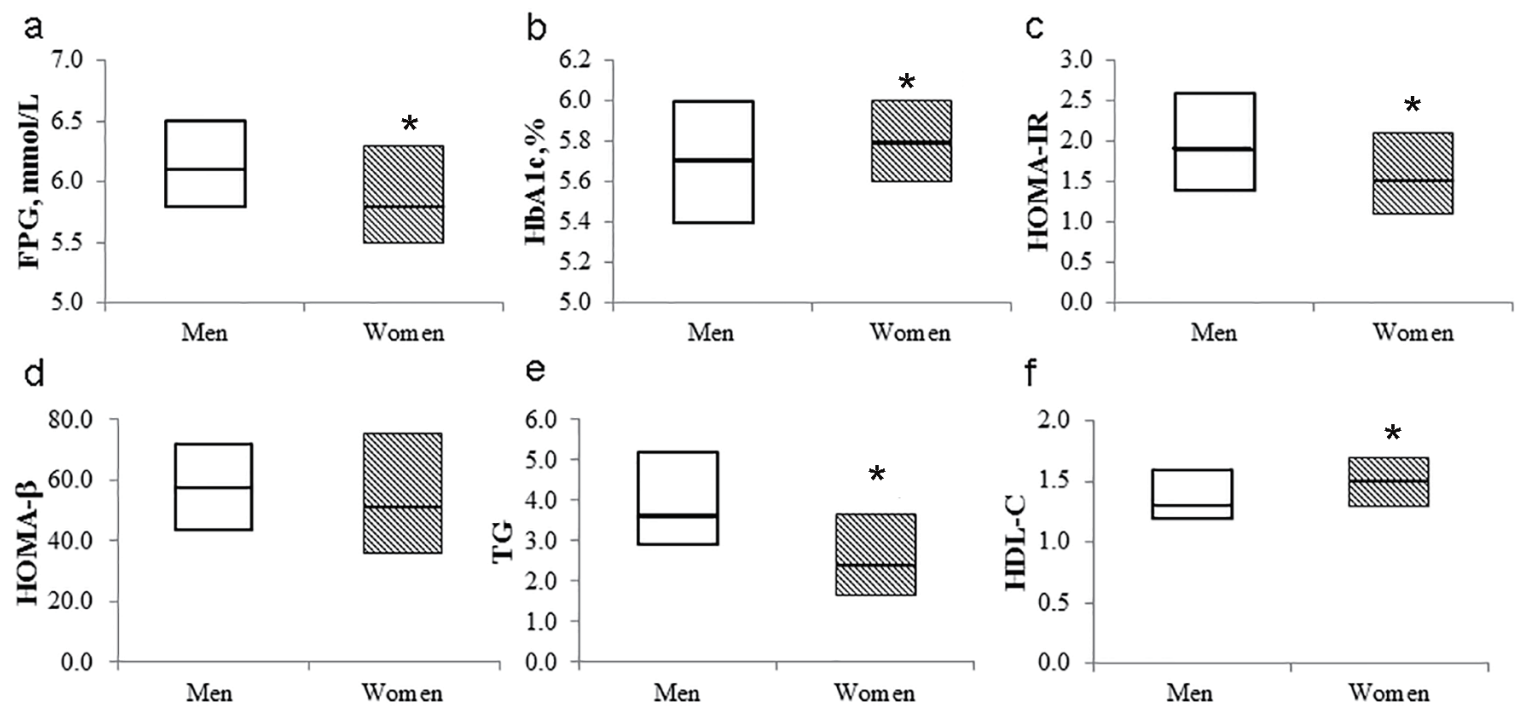

Figure 1. Box plot of metabolic parameters according to sex. The bold horizontal line represents the median, and the box represents the bounds of the 25th and 75th percentiles. FPG: fasting plasma glucose; HOMA-IR: homeostasis model assessmentinsulin resistance; HOMA- $\beta$ : homeostasis model assessment-beta-cell function; TG: triglycerides; HDL: high-density lipoprotein. ${ }^{*} \mathrm{P}<0.05$ (vs. men).

nosis of any type of diabetes or gestational diabetes, 2) a history of gastrectomy, 3) a physical condition such as ischemic heart disease, heart failure, exercise-induced asthma, or orthopedic problems where exercise was not allowed by a doctor, 4) definitive liver and kidney diseases, 5) autoimmune diseases (including hemolytic anemia), and 6) drinking heavily (69 g or more of ethanol per day [14] were excluded.

\section{Measurements}

All participants underwent a complete physical examination, including measurements of height, weight, waist circumference (WC), and blood pressure (BP). The body mass index (BMI) was calculated as the weight divided by the height squared. WC was measured at the umbilical level. Biochemical studies, including a 75-g OGTT, were conducted biannually during the first year and annually thereafter. Blood total cholesterol, highdensity lipoprotein (HDL)-cholesterol, triglycerides, HbA1c, plasma glucose, and insulin levels were measured at a central laboratory (SRL Co., Ltd, Tokyo, Japan). The pancreatic $\beta$-cell function and insulin resistance were assessed using homeostasis model assessment (HOMA- $\beta$ and HOMA-IR) [15]. The dietary intake of each participant was assessed using a semiquantitative food frequency questionnaire (FFQ) [16] with photographs of 122 varieties of dishes and foods. Each item was shown with the actual portion size. Self-reported levels of physical energy expenditure were assessed using a physical activities questionnaire [17]. Current smoking was self-reportedly defined as a smoker.

\section{Statistical analysis}

Variables were presented as the median (25th - 75th percen- tiles). Pearson's correlation coefficient analysis and regression analysis were used to determine the correlation between $\mathrm{HbAlc}$ and interest parameters. Main carbohydrate-containing foods included white rice, bread, noodles, fruit, milk, and snacks. To clarify the relationship of $\mathrm{HbA} 1 \mathrm{c}$ and other parameters, we performed stepwise multiple linear regression analysis. We set it at $\mathrm{P}<0.05$ for univariate analysis and then selected FPG, 2-h PG, BMI, HOMA- $\beta$, white rice intake, and bread intake.

The Statistical Package for the Social Sciences (SPSS 20.0, IBM Corp., New York, USA) program was used. A twotailed P-value $<0.05$ was considered significant. Those cases with missing data were omitted in the relevant analysis.

\section{Ethics}

The study protocol was approved by the Ethics Committee of the National Hospital Organization Kyoto Medical Center, and all subjects gave their written informed consents before the start of the study.

\section{Results}

Men had significantly higher WC (88.4 (83.0 - 92.0) vs. 80.5 (74.3 - 88.0) $\mathrm{mmol} / \mathrm{L} ; \mathrm{P}<0.01)$, FPG (6.1 (5.8 - 6.5) vs. 5.8 (5.5 - 6.3) $\mathrm{mmol} / \mathrm{L} ; \mathrm{P}<0.01), 2-\mathrm{h} \mathrm{PG}(9.1$ (8.4 - 10.0) vs. 8.8 (8.2 - 9.6) mmol/L; P < 0.05), HOMA-IR (1.9 (1.4 - 2.6) vs. $1.5(1.1-2.1) ; \mathrm{P}<0.01)$, triglycerides $(3.6(2.9-5.2)$ vs. $2.4(1.7-3.7) \mathrm{mmol} / \mathrm{L} ; \mathrm{P}<0.01)$, total energy intake $(2,471.1$ $(1,857.8$ - 3,099.9) vs. 2,132.2 (1,810.1 - 2,542.0) kcal; $\mathrm{P}<$ $0.01)$, alcohol intake $(22.5(4.0$ - 51.1) vs. $0.4(0.0$ - 2.9) g; P $<0.01)$, and energy expenditure $(2,289.9(2,107.4-2,544.5)$ vs. 2,149.1 (1,879.4 - 2,433.8) kcal; $\mathrm{P}<0.01)$ than women, 
Table 2. Correlation Between HbA1c Levels and Respective Interest Parameters

\begin{tabular}{|c|c|c|c|c|}
\hline \multirow{2}{*}{ Parameters } & \multicolumn{2}{|c|}{ Men } & \multicolumn{2}{|c|}{ Women } \\
\hline & $\mathbf{r}$ & P-value & $\mathbf{r}$ & P-value \\
\hline \multicolumn{5}{|l|}{ Demographic parameters } \\
\hline Age, years & 0.02 & 0.82 & 0.08 & 0.38 \\
\hline Current smoking, yes & 0.02 & 0.81 & 0.07 & 0.42 \\
\hline BMI, $\mathrm{kg} / \mathrm{m}^{2}$ & 0.29 & $<0.01$ & 0.08 & 0.40 \\
\hline Waist circumference, $\mathrm{cm}$ & 0.26 & $<0.01$ & 0.05 & 0.57 \\
\hline \multicolumn{5}{|l|}{ Metabolic parameters } \\
\hline Fasting plasma glucose, $\mathrm{mmol} / \mathrm{L}$ & 0.33 & $<0.01$ & 0.46 & $<0.01$ \\
\hline 2-h post-load glucose, $\mathrm{mmol} / \mathrm{L}$ & 0.27 & $<0.01$ & 0.22 & 0.02 \\
\hline HOMA-IR & 0.11 & 0.23 & 0.05 & 0.59 \\
\hline НОМА- $\beta$ & -0.06 & 0.52 & -0.27 & $<0.01$ \\
\hline \multicolumn{5}{|l|}{ Dietary factors } \\
\hline Total energy intake, kcal & 0.09 & 0.35 & 0.03 & 0.71 \\
\hline Protein intake, $\mathrm{g}$ & 0.07 & 0.42 & 0.01 & 0.90 \\
\hline Fat intake, $g$ & 0.07 & 0.42 & 0.02 & 0.82 \\
\hline Carbohydrate intake, $\mathrm{g}$ & 0.24 & 0.01 & 0.05 & 0.61 \\
\hline Alcohol intake, $g$ & -0.17 & 0.06 & -0.14 & 0.12 \\
\hline \multicolumn{5}{|l|}{ Main carbohydrate-containing foods } \\
\hline White rice, $g$ & 0.34 & $<0.01$ & -0.06 & 0.56 \\
\hline Bread, g & -0.07 & 0.48 & 0.25 & 0.01 \\
\hline Noodles, g & -0.09 & 0.34 & 0.16 & 0.11 \\
\hline Fruit, $\mathrm{g}$ & 0.14 & 0.14 & -0.05 & 0.65 \\
\hline Milk, g & 0.18 & 0.07 & -0.19 & 0.06 \\
\hline Snacks, $g$ & 0.06 & 0.53 & 0.15 & 0.13 \\
\hline Energy expenditure, kcal & 0.18 & 0.046 & 0.07 & 0.42 \\
\hline
\end{tabular}

BMI: body mass index; HOMA-IR: homeostasis model assessment-insulin resistance; HOMA- $\beta$ : homeostasis model assessment-beta-cell function. " $r$ " is a correlation coefficients.

while women had a significantly higher age (50.0 (46.0 - 56.0) vs. 53.0 (49.5 - 57.0) years; $\mathrm{P}<0.01)$ as well as HbA1c $(5.7$ $(5.4-6.0)$ vs. $5.8(5.6-6.0) \% ; \mathrm{P}<0.01)$ and HDL-cholesterol levels $(1.3(1.2$ - 1.6) vs. $1.5(1.3-1.7) \mathrm{mmol} / \mathrm{L} ; \mathrm{P}<0.01)$ than men (Table 1, Fig. 1a-f). The proportion of current smokers was higher in men than women. There was no difference in the levels of BMI or BP between men and women. BMI, WC,
FPG, 2-h PG, carbohydrate intake, and white rice intake were correlated with the HbA1c level in men, while FPG, 2-h PG, HOMA- $\beta$, and bread intake were correlated with the HbAlc level in women (Table 2).

In multiple regression analyses, BMI, FPG, 2-h PG, and white rice intake were associated with HbA1c levels in men, while BMI, FPG, HOMA- $\beta$, and bread intake were associated

Table 3. Results of Stepwise Multiple Linear Regression Analysis to Evaluate the Effect of Independent Variables on $\mathrm{HbA1c}$

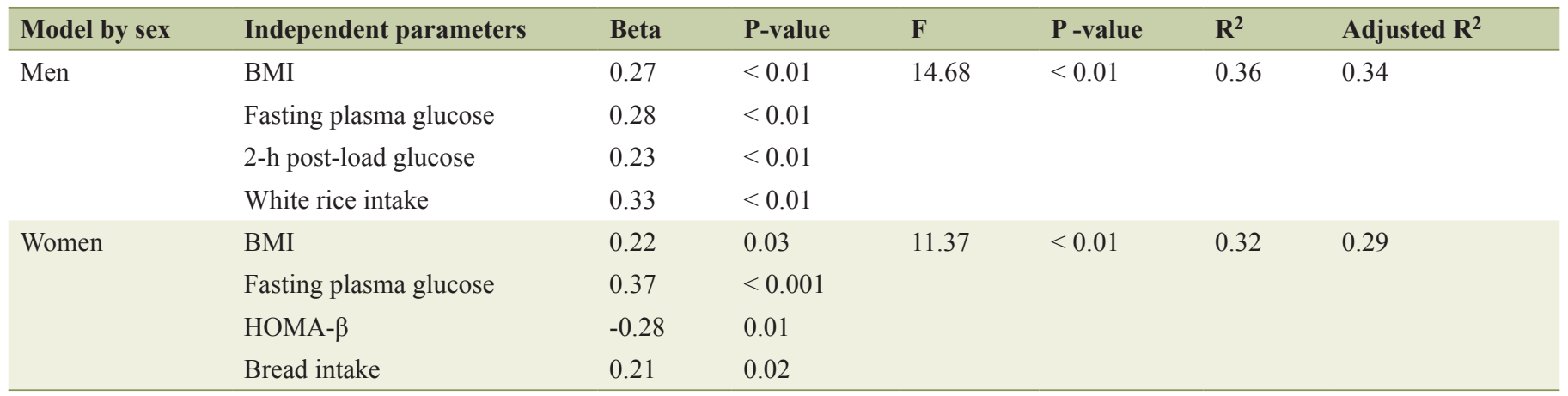

HOMA- $\beta$ : homeostasis model assessment-beta-cell function; BMI: body mass index. 
with $\mathrm{HbA} 1 \mathrm{c}$ levels in women (Table 3).

\section{Discussion}

In multiple regression analyses, $\mathrm{BMI}, \mathrm{FPG}, 2-\mathrm{h}$ PG, and white rice intake were associated with $\mathrm{HbAlc}$ levels in men, while BMI, FPG, HOMA- $\beta$, and bread intake were associated with $\mathrm{HbA1c}$ levels in women. The FPG has been established as a glycemic determinant factor of $\mathrm{HbAlc}$ [18]. In recent-onset diabetic subjects, the $\beta$-cell function, as defined by HOMA- $\beta$, was correlated with the $\mathrm{HbA} 1 \mathrm{c}$ level [19]. In addition, the BMI was found to be correlated with higher HbA1c [20]. These dietary determinants of $\mathrm{HbA} 1 \mathrm{c}$ are relevant when considering the importance of $\mathrm{HbA} 1 \mathrm{c}$ as a diagnostic marker of diabetes [2-4], and that these factors are modifiable. This may be applied when using $\mathrm{HbAlc}$ for the diagnosis and therapeutic monitoring of diabetes in men with impaired glucose tolerance in particular.

The total amount of carbohydrate consumed strongly predicts the glycemic response [21]. A dietary pattern featuring a frequent intake of white rice, which is one of the main carbohydrate foods in Japan, may deteriorate glucose metabolism in Japanese [22]. A higher intake of white rice is correlated with a significantly increased risk of type 2 diabetes, especially in Asian populations [23]. Therefore, an intake of white rice might increase HbAlc levels in male subjects with impaired glucose tolerance. The reason for the correlation between white rice intake and $\mathrm{HbAlc}$ levels in men, but not in women, is unknown. Men tended to have a higher white rice intake than women in the current study. White rice intake may affect the sex differences in the determinants of $\mathrm{HbAlc}$. Bread is another one of the main carbohydrate foods. The consumption of white bread ( $\geq 2$ portions/day) showed a significant correlation with the risk of becoming overweight/obese in Spanish populations [24]. A dietary pattern featuring intake of bread might increase $\mathrm{HbAlc}$ levels in female subjects with impaired glucose tolerance. Further examinations including larger samples are needed to clarify these issues.

The strengths of our investigation include a sample of Japanese adults evaluated using both HbAlc and OGTT. However, this study has several limitations. Firstly, the sample size was small. Secondly, causation cannot be determined because our analysis was cross-sectional. Thirdly, dietary intake was assessed only once, and thus may not have reflected the longterm intake. These limitations should be addressed in future research.

\section{Conclusions}

In conclusion, $\mathrm{HbA1c}$ was influenced by not only residual $\beta$-cell function but also several lifestyle factors, such as carbohydrate intake and alcohol drinking, in subjects with impaired glucose tolerance. These factors can be taken into consideration as modifiable determinants in assessing the $\mathrm{HbAlc}$ level for the diagnosis and therapeutic monitoring of the disease course.

\section{Grant Support}

This work was in part supported by The Ministry of Health, Welfare, and Labour of Japan, JSPS KAKENHI Grant Number 15K08580, and Japanese Council for Science, Technology and Innovation, SIP (Project ID 14533567), Technologies for creating next-generation agriculture, forestry and fisheries (Bio-oriented Technology Research Advancement Institution, NARO).

\section{Competing Interests}

The authors declare that they have no competing interests.

\section{References}

1. Neville SE, Boye KS, Montgomery WS, Iwamoto K, Okamura M, Hayes RP. Diabetes in Japan: a review of disease burden and approaches to treatment. Diabetes Metab Res Rev. 2009;25(8):705-716.

2. The effect of intensive treatment of diabetes on the development and progression of long-term complications in insulin-dependent diabetes mellitus. The Diabetes Control and Complications Trial Research Group. N Engl J Med. 1993;329(14):977-986.

3. Nathan DM, Cleary PA, Backlund JY, Genuth SM, Lachin JM, Orchard TJ, Raskin P, et al. Intensive diabetes treatment and cardiovascular disease in patients with type 1 diabetes. N Engl J Med. 2005;353(25):2643-2653.

4. Intensive blood-glucose control with sulphonylureas or insulin compared with conventional treatment and risk of complications in patients with type 2 diabetes (UKPDS 33). UK Prospective Diabetes Study (UKPDS) Group. Lancet. 1998;352(9131):837-853.

5. Nakagami T, Tajima N, Oizumi T, Karasawa S, Wada K, Kameda W, Susa S, et al. Hemoglobin A1c in predicting progression to diabetes. Diabetes Res Clin Pract. 2010;87(1):126-131.

6. Nishimura R, Nakagami T, Sone H, Ohashi Y, Tajima N. Relationship between hemoglobin A1c and cardiovascular disease in mild-to-moderate hypercholesterolemic Japanese individuals: subanalysis of a large-scale randomized controlled trial. Cardiovasc Diabetol. 2011;10:58.

7. Pani LN, Korenda L, Meigs JB, Driver C, Chamany S, Fox CS, Sullivan L, et al. Effect of aging on A1C levels in individuals without diabetes: evidence from the Framingham Offspring Study and the National Health and Nutrition Examination Survey 2001-2004. Diabetes Care. 2008;31(10):1991-1996.

8. Gulliford MC, Ukoumunne OC. Determinants of glycated haemoglobin in the general population: associations with diet, alcohol and cigarette smoking. Eur J Clin Nutr. 2001;55(7):615-623.

9. Clair C, Bitton A, Meigs JB, Rigotti NA. Relationships of cotinine and self-reported cigarette smoking with hemoglobin A1c in the U.S.: results from the National Health 
and Nutrition Examination Survey, 1999-2008. Diabetes Care. 2011;34(10):2250-2255.

10. Boeing H, Weisgerber UM, Jeckel A, Rose HJ, Kroke A. Association between glycated hemoglobin and diet and other lifestyle factors in a nondiabetic population: crosssectional evaluation of data from the Potsdam cohort of the European Prospective Investigation into Cancer and Nutrition Study. Am J Clin Nutr. 2000;71(5):1115-1122.

11. Gomyo M, Sakane N, Kamae I, Sato S, Suzuki K, Tominaga M, Kawazu S, et al. Effects of sex, age and BMI on screening tests for impaired glucose tolerance. Diabetes Res Clin Pract. 2004;64(2):129-136.

12. Alberti KG, Zimmet PZ. Definition, diagnosis and classification of diabetes mellitus and its complications. Part 1: diagnosis and classification of diabetes mellitus provisional report of a WHO consultation. Diabet Med. 1998;15(7):539-553.

13. Kuzuya T, Nakagawa S, Satoh J, Kanazawa Y, Iwamoto Y, Kobayashi M, Nanjo K, et al. Report of the Committee on the classification and diagnostic criteria of diabetes mellitus. Diabetes Res Clin Pract. 2002;55(1):65-85.

14. Lin Y, Kikuchi S, Tamakoshi A, Wakai K, Kawamura T, Iso $\mathrm{H}$, Ogimoto I, et al. Alcohol consumption and mortality among middle-aged and elderly Japanese men and women. Ann Epidemiol. 2005;15(8):590-597.

15. Matthews DR, Hosker JP, Rudenski AS, Naylor BA, Treacher DF, Turner RC. Homeostasis model assessment: insulin resistance and beta-cell function from fasting plasma glucose and insulin concentrations in man. Diabetologia. 1985;28(7):412-419.

16. Date C, Yamaguchi M, Tanaka H. Development of a food frequency questionnaire in Japan. J Epidemiol. 1996;6(3 Suppl):S131-136.

17. Ainsworth BE, Haskell WL, Leon AS, Jacobs DR, Jr.,
Montoye HJ, Sallis JF, Paffenbarger RS, Jr. Compendium of physical activities: classification of energy costs of human physical activities. Med Sci Sports Exerc. 1993;25(1):71-80.

18. Jansen H, Stolk RP, Nolte IM, Kema IP, Wolffenbuttel $\mathrm{BH}$, Snieder H. Determinants of HbA1c in nondiabetic Dutch adults: genetic loci and clinical and lifestyle parameters, and their interactions in the Lifelines Cohort Study. J Intern Med. 2013;273(3):283-293.

19. Bacha F, Pyle L, Nadeau K, Cuttler L, Goland R, Haymond M, Levitsky L, et al. Determinants of glycemic control in youth with type 2 diabetes at randomization in the TODAY study. Pediatr Diabetes. 2012;13(5):376-383.

20. Hara M, Higaki Y, Taguchi N, Shinchi K, Morita E, Naito M, Hamajima N, et al. Effect of the PPARG2 Pro12Ala polymorphism and clinical risk factors for diabetes mellitus on $\mathrm{HbA} 1 \mathrm{c}$ in the Japanese general population. J Epidemiol. 2012;22(6):523-531.

21. Sheard NF, Clark NG, Brand-Miller JC, Franz MJ, PiSunyer FX, Mayer-Davis E, Kulkarni K, et al. Dietary carbohydrate (amount and type) in the prevention and management of diabetes: a statement by the american diabetes association. Diabetes Care. 2004;27(9):2266-2271.

22. Nanri A, Mizoue T, Yoshida D, Takahashi R, Takayanagi R. Dietary patterns and A1C in Japanese men and women. Diabetes Care. 2008;31(8):1568-1573.

23. $\mathrm{Hu}$ EA, Pan A, Malik V, Sun Q. White rice consumption and risk of type 2 diabetes: meta-analysis and systematic review. BMJ. 2012;344:e1454.

24. de la Fuente-Arrillaga C, Martinez-Gonzalez MA, Zazpe I, Vazquez-Ruiz Z, Benito-Corchon S, Bes-Rastrollo M. Glycemic load, glycemic index, bread and incidence of overweight/obesity in a Mediterranean cohort: the SUN project. BMC Public Health. 2014;14:1091. 